\title{
A Comparative Study of Two Cognitive Models in Teaching Idiomatic Phrasal Verbs: Tyler and Evan's vs. Lakoff and Johnson's Approach
}

\author{
Mohammad Reza Talebinezhad \\ Department of Foreign Languages, Islamic Azad University, Shahreza Branch, Iran \\ Nikoo Farhadian \\ Department of Foreign Languages, Islamic Azad University, Shahreza Branch, Iran
}

\begin{abstract}
This study was an attempt to examine whether Tyler and Evan's approach could have any advantageous contribution to teaching and learning idiomatic PVs in comparison with Lakoff and Johnsons' approach in an Iranian EFL context. To this end, 60 English learners at intermediate level of language proficiency were assigned to two equal groups: group A, treated with Tyler and Evans' approach an group B, treated with Lakoff and Johnsons' approach. Both groups received 40 idiomatic phrasal verbs with the same particles (up, down, in, out, off, away, on). The participants in group A were presented with the underlying systematicity of the particles based on Tyler and Evans' (2003) Principled Polysemy Theory within the Cognitive Linguistics framework. Group B received their instruction following Lakoff and Johnson's (1980) Metaphor Awareness. The data were collected through a pre-posttest assessment and analyzed by T-Test procedure using SPSS demonstrated the superiority of Tyler and Evan's approach and revealed a strategy transfer to unrehearsed PVs as well.
\end{abstract}

Index Terms - phrasal verbs, cognitive linguistics, particles, embodiment motivation conceptualization, spatial scene, vantage point strategy, transfer

\section{INTRODUCTION}

The two-unit words like turn on, turn off, wind up, wind down, etc, are a category of English language lexicon called phrasal verb (PVs). Phrasal verbs with one or two additional components are called particles (Alexander, 1988; McArthur, 1989). These particles are often a spatial preposition such as up, down, on, in, and so forth. PVs are important because English speakers frequently and customarily use them in their everyday communications. In fact, "no one speak or understand English, at least the informal register, without a knowledge of phrasal verbs" (Celce-Marcia \& Larsen-Freeman. 1999, p.425). Hence, learning to recognize, comprehend, and actively use PVs is an inevitable part of EFL pedagogy.

Despite their significant importance, PVs have always been annoying for EFL learners. Ironically, they are like "a nettle that has to be grasped if students are to achieve native-like proficiency in speech and writing"(Cowie, 1993, p.38). On the other hand, idiomaticity which means, (the meaning is not predictable because it is not equal to the sum of the meaning of its components), is the most troublesome characteristic of PVs that make EFL students confused and gives them the false assumption that PVs are random and without logical principles. In sum, difficulties such as, the wide range and abundant number of PVs, their syntax, the formal/ informal stylistic choice, learners' negative attitude and avoidance in using them and the most important, the problem of idiomaticity seems to be all-problematic issues.

Based on the above-described grounds, this paper attempts to address this issue by comparing two approaches in teaching PVs through CL frame work, namely Tyler \& Evans and Lakoff \& Johnsons' models.

\section{RESEARCH QUESTIONS AND HYPOTHESES}

The study outlined in this paper was designed to provide answers to the following questions:

Question 1: To what extent do Tyler \& Evans' and Lakoff \&Johnsons' models differ in their effectiveness in teaching phrasal verbs?

Question 2: To what extent do the students who receive their treatment using the two models differ in transferring their acquired knowledge to unrehearsed novel phrasal verbs?

Taking these questions into account, the following hypotheses were formulated.

Hypothesis 1: Tyler and Evans' model is more useful in teaching PVs than Lakoffs' model.

Hypothesis 2: Learners treated using the two different models will differ in transferring their acquired knowledge to novel contexts. 


\section{REVIEW OF LITERATURE}

The subject of how best to teach PVs has attracted considerable attention and many researchers have tried to facilitate this tedious task of learning PVs for students. Some of the authors working on the field of PVs agree that there is no specified single way or a programmed manner in which a student can learn PVs and the only way to acquire such knowledge is by extensive reading and listening (Al-Sibai, 2003).

Sadri (2012) stated, "a traditional way of presenting- and not actually teaching PVs-which has been the most common approach in English course books and materials so far is providing the students with a list of PVs, based on alphabetical order or a verb with different particles or a particle with different verbs". An example is Coles and Lord's (1978, p.66), Open Road students have to match the PVs with the definitions at the beginning of the exercise. Or in Sue O'Connell's (1987, p. 27), Focus on First Certificate where a list of PVs using the verb put is given, together with a definition and the students had to learn this heart. In 1970's, after recognizing the inadequacy of traditional method, presentation of new language items in context seemed very promising for teaching PVs. Among the more recent studies in this connection, Wyss' (2002) work is worth mentioning. He advised teachers to present their students with various authentic texts- articles, books, etc- that contain a rich mix of PVs. Also, Cirocki (2003) developed a technique for teaching PVs that was somewhat different from Wyss; that students were able to pick up the meaning of a PV from context even though they had never seen it before. However, guessing meaning from context has its own limitation that single encounter with an unfamiliar word in context seldom reveals more than a fraction of the word's meaning and also learning from context is demonstrably more difficult in second language learning.

The last view in teaching PVs was cognitive linguistic (CL). CL believes that much of the meaning of words is constructed and driven from bodily and sociocultural experience and is non-linguistic in nature. The well-known people in this area were Lakoff and Johnsons and Tyler and Evans' approach. The first book of Lakoff and Johnson (1980) was, Metaphors we live by. The significant message of the book was, humans not only speak in metaphorical terms, but also think in metaphorical terms. The next book was, The body in the mind in 1987 that first introduced the notion of image schema as the building block of metaphor. The term schema in image schema means that "image schemas are not rich or detail concepts, but rather abstract concepts consisting of patterns emerging from repeated instances of embodied experience" (Evans \& Green, 2006, p.179) or in Mandler's (2004, p.79) terms image schema is "not a simplified visual image but a schematic spatial representation that summarizes spatial relations and movements in space". At the end, although Lakoff and Johnson's theory was influential, there were some shortcomings. One of these problems refer to the granularity (i.e, the level of detail) of image schemas (Evans \& Green, 2006, p.336). Another criticism was relate to methodological constraints and lack of clear methodological principles which means, the Lakoffian approach based on intuitions and imaginations rather than actual representing of objects in the mind of language user (Evans \& Green, 2006). And the last one was, the absence of vantage point and contextual inferences.

In 2003, Tyler and Evans provided a comprehensive theoretical analysis (termed as principled polysemy theory) for English particles/prepositions in their remarkable book: The semantics of English prepositions: spatial senses, embodied meaning, and cognition. In this theory they proposed that, the polysemy of particles should be characterized based on two principles: vantage point (way of viewing a spatial scene) and contextual inferences (understanding meaning from context of use). The critical difference between Tyler and Evan's theory and the Lakoffian approach is that, in Diven's (2001b) terms, it is a-metaphorical. While they do not reject the importance of metaphor in human cognition, they hold that metaphors are vague and unspecified concepts and do not adequately explain the cognitive mechanisms and processes of underling systematicity of particles/prepositions.

A few Iranian researches were done in the field of PVs within a CL framework, some of them as far as the researcher could find from the body of research available, was Sadri's MA dissertation which is called A pedagogical application of cognitive linguistics in teaching idiomatic phrasal verbs (2012). In this study she compared Tyler and Evans' method in teaching idiomatic phrasal verbs with traditional (memorization) approach with only four particles up, down, in and out. Another study was related to Farsani's $\mathrm{PhD}$ dissertation which named as Mnemonic effectiveness of CL-motivated picture - elucidation tasks in foreign learners' acquisition of English phrasal verb. In this study they presented the students with some pictures showing literal sense of a PV and on the next session they presented another picture showing more abstract figurative meaning of the same PV. Nevertheless, regarding the fact that newly-developed and small bulk of CL-based research in Iranian literature awaits much more up-to-date studies, the present study is an attempt to add one such study to this archive.

\section{METHOD}

\section{A. Participants}

The participants who took part in study were 60 students of a private language school (Daneshjoo Language Center) in Isfahan, Iran. They all shared Persian as their mother tongue and Their age ranged from 17 to 23 . The study was conducted during the summer English courses of the language institute.

In order to ensure participants' homogeneity in terms of language proficiency, the Oxford Placement Test (OPT, 2010) was run on a total population of approximately 300 candidates who had enrolled for the summer program of the institute. Based on the results of the OPT, 100 number of candidates were placed at intermediate level of English language 
proficiency. Then, using a table of random number, 60 candidates were randomly selected from them as the participants of this study.

\section{B. Materials}

The study took advantage of pre and posttest assessment as its data collection instrument. The pretest used in this study consisted of multiple-choice items in order to understand the difficult items and the degree of familiarity of students with target PVs, these 40 idiomatic phrasal verbs with particles up, down, in, out, off, away, on were selected based on participant's textbook that were taught during one term (Top Notch series) and the posttest consisted of 6 cloze passages with fill-in-the-blank/word bank format (first part of the test) and also 14 paraphrase sentences (second part of the test).

\section{Research Design and Procedure}

Before administering the pretest, participants were briefed about PVs; highlighting that a PV consists of a verb plus a smaller word (such as up, down, in, out,...) and giving examples they had already been practically familiar with, such as get up, stand up, sit down, come in. The participants were assured that their scores on the experimental tests would have no negative effect on their end-of-term results, and then the test was distributed. The participants were randomly assigned to two equal groups/ classes.

1. The first group/class arranged to receive treatment in the form of CL- motivated instruction on 40 idiomatic PVs ending in particles up/down, in/out, off, away and on based on Tyler and Evan's model.

2. The second group/class which was to receive instruction on the same PVs as in the first group but through Lakoff's approach.

The experimental procedure for both groups was performed in the form of teacher-fronted instruction and began from the first session. Table 1. summerizes the time sequence of this instructional procedure.

TABLE 1.

TIME SEQUENCE OF INSTRUCTIONAL PROCEDURE FOR BOTH GROUPS

\begin{tabular}{|l|l|l|l|l|l|l|l|}
\hline Group & session & session & session & session & session & $\begin{array}{l}\text { session } \\
16-17\end{array}$ & $\begin{array}{l}\text { session } \\
18-20\end{array}$ \\
\hline The fist and second & $1-3$ & Out & Up & On & Off & In & Away \\
& $(6 \mathrm{PVs})$ & $(12 \mathrm{PVs})$ & $(5 \mathrm{PVs})$ & $(6 \mathrm{PVs})$ & $\begin{array}{l}\text { Down } \\
(2 \mathrm{PV})\end{array}$ & $(5 \mathrm{PV})$ \\
\hline
\end{tabular}

For the first group, the target idiomatic PVs of the study were taught based on CL-based explanations which was basically adapted from Tyler and Evens' (2003) theory which is proposed in their book titled : The semantic of English prepositions : spatial scenes, embodied meaning and cognition. However, as the name of the book reveals, it takes focus on prepositions (and not their function as particles in a verb- particle combinations). Each particle refers to a specific spatial scene which is meaningful for humans because of their similarity and correspondence to bodily actions or physical experiences. This basic meaning of particle can be extended to form a semantic network, that is, each particle has some additional non- spatial (abstract) meanings other than its basic meaning which are the conceptual and cognitive results of the basic meaning. It was clarified to class that these explanations are only clues to learn and infer the meaning of PVs and there is no need or obligation to memorize them.

The CL-based explanations were accompanied with simple drawings of spatial scenes of each particle and the vantage point configurations. CL believes in fundamental role of space and bodily mechanisms in human cognition; therefore, the researcher confined her visual presentation to simple drawing she drew on the white board whenever necessary.

As for the second group, the 40 target idiomatic PVs of the study were taught to the participants under the same time schedule but through Lakoff's metaphor awareness which was basically adapted from Lakoff and Johnson's (1980) theory which is proposed in their book titled metaphor we live by. In that book they emphasized that the foundation of human mind is metaphoric in nature and metaphors emerge from pre-linguistic representations of human bodily experience. On the other hand, they mentioned that the meanings of particles/prepositions are clearly grounded in spatio-physical interaction with the world. Gradually during the specified time each particle was explained without being contextualized and the vantage point configuration.

At the end of the program a posttest was administered. It should be mentioned that the posttest consisted of two parts; the first part that aimed at eliciting the data related to the first researcher's question covered the 40 idiomatic PVs taught during the program. It consisted of six short dialogs and paragraphs with some blanks that students were asked to fill them with a PV they could choose from a given word bank. The participants were asked to select only one and the most appropriate PV for each blank. The second part of the test was designed to collect the required data for the second research question of the study. This section consisted of 14 idiomatic PVs that were not presented in class and students were not familiar with. The second research question addressed whether the participants could transfer their knowledge of learned PVs to unfamiliar PVs; therefore, they were somewhat expected to guess the meaning of the new PVs based on the underlying systematicity of the particles.

D. Data Analysis 
The data in the form of participants' scores from pre/posttest were fed into SPSS (IBM SPSS statics: version 20.0). The data were analyzed in terms of mean score differences and their corresponding P-values by running T-Test for independent samples between the first group and the second groups. Since the study sought answers to two research questions, two sets of analyses were performed, each dealing with one of the research questions. The results of these analyses are presented in the following part.

\section{RESULTS}

\section{A. Results for the First Research Question}

To answer the first question, the results of two groups' performances on pre/posttest were to be compared. At first, the scores of two groups on pretest were fed to SPSS (Table.2). Then the results were analyzed by independent samples T-Test (Table.3). As is evident from table 2, Sig (2-tailed) value is .180 that represents, p-value is not significant, because it's bigger than $.05(\mathrm{p}>.05)$. Therefore, the groups' performances were relatively close on pretest.

TABLE. 2 .

DESCRIPTIVE RESULTS OF THE GROUPS ON PRETEST

\begin{tabular}{|c|c|c|c|c|c|}
\hline & class & $\mathrm{N}$ & Mean & Std. Deviation & Std. Error Mean \\
\hline Pretest first & 1.00 & 30 & 17.9667 & 1.95613 & .35714 \\
\hline Second & 2.00 & 30 & 17.3333 & 1.64701 & .30070 \\
\hline
\end{tabular}

TABLE.3.

INDEPENDENT T-TEST DESCRIPTIVE RESULTS FOR PRETEST

\begin{tabular}{|l|l|l|l|}
\hline & $\mathrm{t}$ & $\mathrm{df}$ & $\operatorname{Sig}(2$-tailed) \\
\hline Equal variance assumed & -1.357 & 58 & .180 \\
Equal variance not assumed & -1.357 & 56.36 & .180 \\
\hline
\end{tabular}

The second step was to examine the groups' performance on the posttest (part1). Like the previous part the scores obtained from posttest were fed into SPSS (Table.4). in order to compare the groups' performances statistically, independent T-Test was run (Table.5).Comparing the results Illustrates that there is statistically significant difference between the groups, In order to, the p-value is smaller than $.05(\mathrm{p}<.05)$. So it was indicated that after the treatment, the first group did better and outperformed the second group.

TABLE.4.

MEAN SCORES OF THE GROUPS ON POSTTEST (PART 1) Group Statistics

\begin{tabular}{|ll|l|l|l|l|}
\hline & class & N & Mean & Std. Deviation & Std. Error Mean \\
\hline Posttest1 first & 1.00 & 30 & 31.4000 & 1.56690 & .28608 \\
\hline Second & 2.00 & 30 & 21.3000 & 1.84110 & .33614 \\
\hline
\end{tabular}

TABLE.5.

INDEPENDENT T-TEST DESCRIPTIVE RESULTS FOR POSTTEST, PART1

\begin{tabular}{|l|l|l|l|}
\hline & $\mathrm{d}$ & $\mathrm{df}$ & $\operatorname{Sig}(2$-tailed $)$ \\
\hline Equal variance Assumed & -22.882 & 58 & .000 \\
Equal variance not assumed & -22.882 & 56.554 & .000 \\
\hline
\end{tabular}

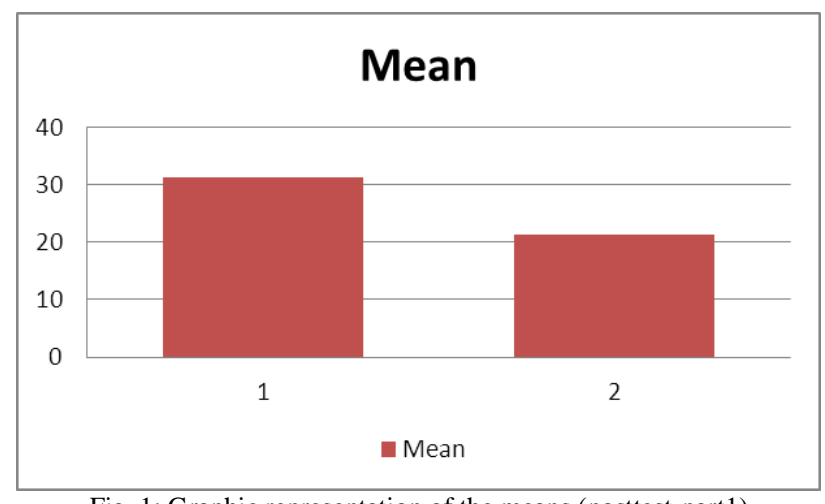

Fig. 1: Graphic representation of the means (posttest-part1)

Figurel is the graphical representation of the groups' overall performance on posttest (part1).

\section{B. Results for the Second Research Question}


The data from the second question was demonstrated in table6. Obviously, it can be understand that the first groups' mean score is much more than the mean score of the second group.

TABLE 6.

MEAN SCORES OF THE GROUPS ON POSTTEST (PART 2)

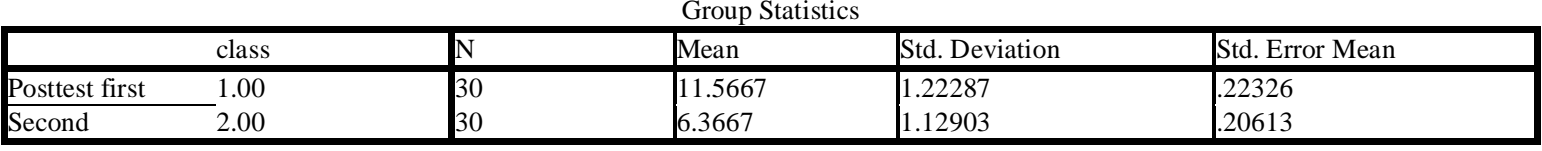

To compare the results statistically an independent samples T-Test was run (Table7). It shows a Sig (2-tailed) value of .000, which entails a statistically significant difference $(\mathrm{p}<.05)$ between the performances of the groups on posttest (part2).

TABLE.7.

INDEPENDENT T-TEST DESCRIPTIVE RESULTS FOR POSTTESTPART2

\begin{tabular}{|ll|l|l|l|}
\hline \multicolumn{3}{|c|}{ class } & df & Sig(2-tailed) \\
\hline Posttest first & 1 & -17.113 & 58 & .000 \\
\hline Second & 2 & -17.113 & 57.634 & .000 \\
\hline
\end{tabular}

It could be concluded that the first class had a better learning gain of the taught idiomatic PVs than the second class. Besides, the first group exhibited a better knowledge transfer to novel idiomatic PVs than their second group peers. The overall performance of groups on posttest (part2) is graphically presented in figure 2.

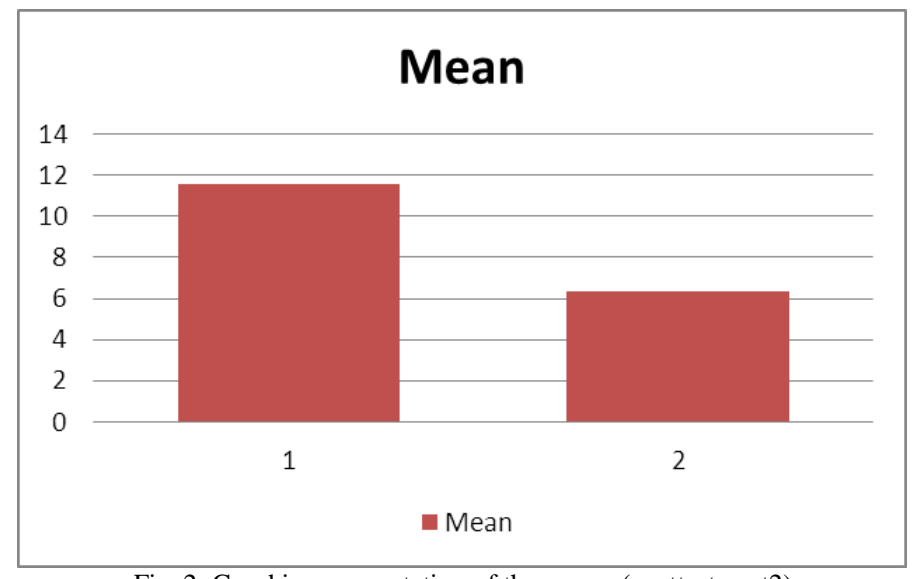

Fig. 2: Graphic representation of the means (posttest-part2)

\section{DISCUSSION}

The current study was an attempt to examine the pedagogical application of CL in teaching idiomatic PVs. The results obtained from the data analysis procedure provide a clear answer to the first posed question of the study: that Tyler \& Evans approach to teaching idiomatic PVs can indeed enhance the learning of idiomatic PVs.

The students of the first class were made aware that multiple meanings associated with particles in idiomatic PVs are motivated by everyday normal experiences in the environment and related in systematic ways within a meaning network (Tyler\& Evans, 2003). Moreover, the study provided the first class participants with the schematic drawings that represented the spatial scene of each particle in terms of a TR (trajectory), moveable object and a LM (land mark), immovable element, as well as the incorporation of the viewer's vantage point and figure-ground profiles.

Cognitive psychology and the light it has thrown on cognitive processes concerning memory provides a cogent explanation for such effective learning. There are two cognitive processes particularly relevant to the current study: dual coding theory and levels of processing theory. In dual coding theory (Paivio, 1971; as cited in Sternberg, 2006) it is held that there are two ways a person could expand on learned material: verbal associations and visual imagery. Since the treatment of the first class was a combination of teacher-fronted verbal explanations and representative drawings of spatial scenes from different vantage points, it can be concluded that visual and verbal information are processed differently and along distinct channels in the human mind, creating separate representations for information processed in each channel and both visual and verbal codes can be used when recalling information.

Another relevant theory is levels-of-processing theory which means, the deeper the level at which information is mentally processed, the more likely the information is to be committed to long-term memory (Craik \& Lockhart, 1972). Two levels of processing are: deep processing which entails durable semantic associations in memory and meaningful learning, and shallow processing based on no associative clues leading to rapid forgetting. 
The above-described facts shed more light on why the second group displayed lower learning gain on PVs than the first group. The students received the target idiomatic PVs through Lakoff \& Johnson's metaphor awareness. However, metaphors are fairly vague and ambiguous concepts. Besides, there are numerous metaphors involved in understanding the meaning of a particle. Therefore, providing the learners with metaphors and asking them to learn them practically is no better than asking them to memorize PVs from a list as non-systematic lexical items.

Going back to the second research question, the findings indicate a successful transfer of knowledge for the first group as well as a poor transfer for the second group. From Tyler \& Evens' point of view, meanings are not fixed prescribed patterns to be memorized; rather, they are constructed based upon careful thought, observations of the world, and background sociocultural knowledge. The better performance of the first class on unfamiliar idiomatic PVs could be attributed to the fact that being equipped with Tyler \& Evans' approach, they managed to infer the meaning of unfamiliar idiomatic PVs from the context. When they are making inferences, they combine what they have been taught about the systematicity of idiomatic PVs, their background knowledge, and their experiences about the world. Analogously, using Lakoffian approach that advocates metaphor awareness as the only way of learning idiomatic PVs tend to force the learners to believe that different senses of particles, appear to be unmotivated and unrelated. Therefore, when they see new idiomatic PVs in unrehearsed contexts they automatically skip them over without thinking because the unfamiliar idiomatic PVs do not ring a familiar bell in their memory.

\section{CONCLUSION}

This study attempted to examine whether a recent CL-based approach, namely principled polysemy theory (Tyler \& Evans, 2003), could have any advantageous contribution to teaching and learning idiomatic PVs in comparison with an approach in which idiomatic PVs are instructed through Lakoff \& Johnsons' metaphor awareness approach. Lakoffian method underscores the importance of embodiment principle of CL and relying on image schemas and metaphors as the results of bodily experience provides a very narrow simplistic interpretation of embodiment tenet of CL.

The findings of the study lend strong support to the superiority of the Tylers' approach and confirmed that participants of the first group who received idiomatic PVs through CL-based instruction and students' background knowledge and contextual inferences not only learned idiomatic PVs better but also were able to effectively transfer their acquired knowledge to unrehearsed idiomatic PVs as well. Also it was shown that particles are not arbitrary but motivated by language users' experience of their physical, social and cultural surroundings, and hence, making the learners familiar with the principles of spatial and abstract meaning underlying the particles would facilitate learning and teaching of idiomatic PVs.

\section{REFERENCES}

[1] Alexander, L.G. (1988). Longman English Grammar. London: Longman.

[2] Al- Sibai, D.M. (2003). Using the balanced activity approach in teaching phrasal verbs to Saudi college students: A review of literature. Retrieved June 27, 2012 from http://www.pdfplace.net/using-the-balanced-activity-approach

[3] Celce-Murcia, M.\& Larsen-Freeman, D. (1999). The grammar book: an ESL/EFL teacher's course. Boston: Heinle and Heinle.

[4] Cirocki, A. (2003). Teaching phrasal verbs by means of constructing texts. ELTNewsletter. Retrieved April10, 2003, from http://www.eltnewsletter.com/column. shtml.

[5] Coles, D.\& Lord, B. (1976). Open road. Oxford: Oxford University Press.

[6] Cowie, A.P.,(1993). Getting to grips with phrasal verbs. English Today, 9(4), 38-41.

[7] Craik, F.I.M., \& Lockhart, R.S. (1972). Levels of processing: Aframework for memory research. Journal of verbal Learning and verbal behaviour, 11, 671-684.

[8] Dirven, R. (2001b). The Metaphoric in Recent Cognitive Approaches to English Phrasal Verbs.Metaphoric.de,1, $39-54$. Retrieved June 28, 2012 from: http://www.metaphorik. de/01/driven.htm.

[9] Farsani, H.M., Moinzade, A., \&Tavakoli, M. (2012). Mnemonic effectiveness of CL-motivated picture-elucidation tasks in foreign learners' acquisition of English phrasal verbs. Theory and practice in language studies, 2 (3), 498-509.

[10] Lakoff, G. \& Johnson, M. (1980). Metaphors we live by. Chicago: University of Chicago Press.

[11] Lakoff, G. \& Johnson, M. (1999).Philosophy in the flesh: The embodied mind and its challenge to western thought. Chicago: Basic Books.

[12] McArthur, T. (1989). The long- neglected phrasal verbs. English Today, 18, 38-44.

[13] O'Connell, S. (1987). Focus on first certificate. London: Collins.

[14] Sadri, E. (2012). A pedagogical application of cognitive linguistics in teaching idiomatic phrasal verbs. Unpublished M.A thesis. University of Sheikhbahaee, Isfahan.

[15] Sternberg, R.J. (2006). Cognitive psychology. (4thed.). Belmont, CA: Wadsworth

[16] Tyler, A. \& Evans, V. (2003). The Semantics of English prepositions: Spatial scenes, embodied meaning and cognition. Cambridge: Cambridge University Press.

[17] Wyss, R. (2002). Teaching English multi-word verbs is not a lost cause after all. ELT Newsletter. Retrieved November 17, 2003, from http://www.eltnewsletter.com/back/march2002/art902002.htm. 
Mohammad Reza Talebinejad is an Associate Professor of Applied Linguistics at Islamic Azad University, Shahreza Branch. $\mathrm{He}$ is also an associate faculty member at Sheikhbahaee University, Iran.

Dr Talebinejad received his BA in English Language and Literature, University of Isfahan in 1975. He then got his MA in TEFL from the University of Texas at Austin, USA in 1977. For his doctoral degree, Dr Talebinejad was admitted to the University of Sheffield, UK, where he did his PhD in Applied Linguistics in1994.

He has widely published in Iranian as well as International professional journals such as Metaphor and Symbol, English Teaching Forum, Language Testing, IJAl, Language and Translation, Journal of Social Sciences, The International Journal of Humanities, and other local and international journals. Dr Talebinejad has presented papers in international conferences such as AILA, 2000; Atiner, 2011; RAAM, 2002, 2001 in Paris and Tunis, EUROSLA, Switzerland, 2006; Multicultural Conference, 2007, China. In addition, Dr Talebinejad has authored/coauthored eight books in related fields and ESP.

Nikoo Farhadian was born in Isfahan, Iran, in 1978. She received an M.A. In TEFL from Islamic Azad University, Shahreza Branch, Iran, in 2013. She is a private language school teacher and has been teaching English for about 5 years. 